\title{
Biomolecular identification of (CCTG)n mutation in myotonic dystrophy type 2 (DM2) by FISH on muscle biopsy
}

\author{
R. Cardani, ${ }^{*}$ E. Mancinelli, ${ }^{*}$ V. Sansone, ${ }^{* *}$ G. Rotondo, ${ }^{* *}$ G. Meola** \\ *Dipartimento di Fisiologia e Biochimica Generali, Università di Milano, Italy; ** Istituto Policlinico San \\ Donato, Dipartimento di Neurologia, Cattedra di Clinica Neurologica, Università di Milano, Italy.
}

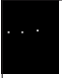

(C)2004, European Journal of Histochemistry

Myotonic dystrophy type 2 (DM2) is a dominantly inherited disorder with multisystemic clinical features, caused by a CCTG repeat expansion in intron 1 of the zinc finger protein 9 (ZNF9) gene. The mutant transcripts are retained in the nucleus forming multiple discrete foci also called ribonuclear inclusions. The size and the somatic instability of DM2 expansion complicate the molecular diagnosis of DM2. In our study fluorescence-labeled CAGG-repeat oligonucleotides were hybridized to muscle biopsies to investigate if fluorescence in situ hybridization (FISH), a relatively quick and simple procedure, could be used as a method to diagnose DM2. When FISH was performed with (CAGG) ${ }_{5}$ probe, nuclear foci of mutant RNA were present in all genetically confirmed DM2 patients $(n=17)$ and absent in all patients with myotonic dystrophy type $1(\mathrm{DM} 1 ; \mathrm{n}=5)$ or with other muscular disease $(n=17)$ used as controls. In contrast, foci were observed both in DM1 and DM2 myonuclei when muscle tissue were hybridized with $(\mathrm{CAG})_{6} \mathrm{CA}$ probe indicating that this probe is not specific for DM2 identification. The consistent detection of ribonuclear inclusions in DM2 muscles and their absence in DM1, in agreement with the clinical diagnosis and with leukocyte (CCTG)n expansion, suggests that fluorescence in situ hybridization using $(C A G G)_{5}$ probes, may be a specific method to distinguish between DM1 and DM2. Moreover, the procedure is simple, and readily applicable in any pathology laboratory.

Key words: myotonic dystrophy type 2; diagnostic method; fluorescence in situ hybridization; FISH; CAGG probe; ribonuclear inclusions.

Correspondence: Prof. Giovanni Meola, Professor and Chair of Neurology, Dept. Neurology, University of Milan, Istituto Policlinico San Donato, Via Morandi, 30,

20097 San Donato Milanese, Milan - Italy

Phone: ++02.52774480

Fax: ++02.5274717

e-mail: giovanni.meola@unimi.it

Paper accepted on September 9, 2004.

European Journal of Histochemistry

2004; vol. 48 issue 4 (Oct-Dec):437-442
$\mathrm{M}$ yotonic dystrophy type 2 (DM2) is an autosomal dominant, multisystemic disease. It is characterized by muscle weakness, myotonia and by non-muscle manifestations including cataracts, cardiac arrhytmias and hypogonadism (Meola et al., 1999; Moxley et al., 1998, 2002; Meola, 2000; Day et al., 2003; Udd et al., 2003). Muscle biopsies are characterized by fibers with increased number of central nuclei, angulated atrophic fibers, occasional ring fibers, type I fiber predominance and a preferential atrophy of type II fibres. (Day et al., 2003; Schoser et al., 2004; Vihola et al., 2003). Nuclear clump type II fiber atrophy is considered typical of DM2, although, in our experience, $20 \%$ of patients with clinical and genetic confirmation of DM2 mutation have normal histograms and no nuclear clump type 2 fiber atrophy (Meola et al., 2004).

The DM2 locus is mapped to a $10 \mathrm{c}-\mathrm{M}$ region of chromosome 3q (Ranum et al., 1998) and recently Liquori et al. (2001) have reported that DM2 is caused by a large expansion of a CCTG repeat located in intron 1 of the zinc finger protein 9 (ZNF9) gene. ZNF9 contains seven zinc finger domains and is thought to be an RNA binding protein that is expressed in many different tissues. In DM2, expanded allele sizes range from 75 to 11000 CCTG repeats, with a mean of approximately 5000 repeats (Liquori et al., 2001). The mutant ZFN9 gene is transcribed into RNA that contains expanded CCUG repeats and these transcripts are retained in the muscle nucleus, producing foci of mutant RNA also called ribonuclear inclusions (Liquori et al., 2001; Mankodi et al., 2001, 2003). A large body of evidence indicates that these ribonuclear inclusions are responsible for the clinical manifestations of DM2. It has been suggested that CCUG expansion expressed at RNA level could themselves be pathogenic and cause the multisystemic features of DM2 (Liquori et al., 2001). Moreover recent studies have demonstrated that intranuclear RNA foci bind specific 
Table 1. $F=$ female; $M=$ male; $L L W=$ lower limb weakness; $M R C=$ Medical Research Council Scale (Medical Research Council. Aids to the examination of the peripheral nervous system. Memorandum 45. 1976, Pendragon House, London.); CK = creatine kinase; AV $=$ atrioventricular; OGTT $=$ oral glucose tolerance test; $\gamma-\mathrm{GT}=\gamma$-glutamyl transferase; SVEB = supraventricular ectopic beats.

\begin{tabular}{|c|c|c|c|c|c|c|c|}
\hline Patient & $\begin{array}{l}\text { Age/ } \\
\text { sex }\end{array}$ & $\begin{array}{l}\text { Disease } \\
\text { duration }\end{array}$ & $\begin{array}{l}\text { Agé } \\
\text { at onset }\end{array}$ & $\begin{array}{l}\text { Symptoms } \\
\text { at onset }\end{array}$ & MegamRC & MRC biceps & multisystem involvement \\
\hline $\mathrm{BC}$ & $59 / F$ & 14 & 45 & proximal LLW & 118 & 4,5 & hypoacusia, hyperthyroidism, CK x4 \\
\hline $\mathrm{Cl}$ & $47 / \mathrm{F}$ & 10 & 37 & distal LLW & 134 & 4,5 & diabetes, hyperthyroidism, cataracts, memory loss \\
\hline CS & $49 / \mathrm{F}$ & 10 & 39 & proximal LLW & 118 & 4 & cataracts \\
\hline $\mathrm{FE}$ & $60 / M$ & 6 & 54 & lower limb stiffness & 150 & 5 & visual-spatial deficits \\
\hline GL & $55 / F$ & 10 & 45 & proximal LLW & 118 & 4 & cataracts, visual spatial deficits \\
\hline GE & $36 / M$ & 21 & 15 & myotonia & 150 & 5 & 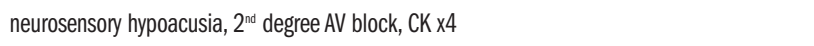 \\
\hline GM & $43 / \mathrm{F}$ & 25 & 18 & myalgia & 138 & 5 & $\begin{array}{l}\text { neurosensory hypoacusia, sacral cysts, uterine fibroma, high glucose levels after 0GПT, CK x2, } \\
\text { triglycerides x2, visual-spatial deficits, WMHL on brain MRI }\end{array}$ \\
\hline NG & $62 / M$ & 12 & 40 & proximal LLW & 124 & 4 & $\begin{array}{l}\text { neurosensory hypoacusia, paresthesias of the hands, coronary heart disease, cataracts, } \\
\text { cerebellar vermis and corpus callosum atrophy, cholesterol x2, triglycerids x3, CX x2 }\end{array}$ \\
\hline PV & $47 / M$ & 17 & 30 & myotonia & 132 & 4,5 & testicular motility, baldness, CK x5, $\gamma$-GT x2, cholesterol x2, \\
\hline PL & $65 / M$ & 15 & 50 & proximal LLW & 105 & 4,5 & $\begin{array}{l}\text { cataracts, baldness, diabetes, high blood pressure, triglycerides } \times 4 \text {, mild mitral prolapse, } \\
\text { choreic movements, oro-mandibular dyskinesia }\end{array}$ \\
\hline RG & $63 / M$ & 27 & 36 & proximal LLW & 127 & 4,5 & $\begin{array}{l}\text { cataracts, feet paresthesias, truncal lipomas, erectile dysfunction, visual-spatial deficits, } \\
\text { bradycardia, neurosensory hypoacusia, lower limb venous incontinence, restless leg syndrome, } \\
\text { CK x3, } \gamma \text {-globulin < 10\%, low back pain }\end{array}$ \\
\hline RL & $32 / \mathrm{F}$ & 6 & 26 & myotonia & 150 & 5 & none \\
\hline RO & $40 / \mathrm{F}$ & 15 & 35 & proximal LLW & 146 & 4,5 & $\begin{array}{l}\text { cataracts, visual spatial deficits, low back pain, hand paresthesias, neurosensory hypoacusia, } \\
\text { infertility, tachycardia, CK x2, } \gamma \text {-globulin }<10 \%\end{array}$ \\
\hline RR & $44 / F$ & 28 & 16 & proximal LLW & 77 & 2,5 & $\begin{array}{l}\text { visual spatial-deficits, low-back pain, cervical herniated discs, diffuse trunk and limb lipomas, } \\
\text { initial baldness, fine distal tremor, SVEB, CK x2 }\end{array}$ \\
\hline RS & $43 / M$ & 21 & 22 & proximal LLW & 146 & 4,5 & visual spatial-deficits, low-back pain, lumbar herniated discs, initial baldness, SVEB, CK x2 \\
\hline RA & $20 / \mathrm{F}$ & 2 & 18 & myotonia & 150 & 5 & none \\
\hline RAm & $71 / \mathrm{F}$ & 46 & 25 & proximal LLW & 112 & 3 & extrapyramidal signs, cataracts, 1st AV block, chronic obstructive broncopulmonary disease \\
\hline
\end{tabular}

RNA binding proteins and muscleblind that are sequestered in DM2 nuclei, leading to depletion of transcripts that require these proteins for normal gene expression (Mankodi et al., 2001, 2003; Fardaei et al., 2002; Kanadia et al., 2003).

The discovery of DM2 mutation raised the possibility to use molecular testing for a more accurate diagnosis of patients with suspected DM2 since the clinical and histological features of DM2 are similar even if not identical to those of myotonic dystrophy type 1 (DM1) and it is not always easy to distinguish by routine histological and histochemical technique on muscle biopsy these two diseases (Meola, 2000; Moxley et al., 2002). This is especially true when family trees are uninformative and core clinical findings, like clinical EMG are extremely fluctuating and maybe absent when the patient is first seen. Similarly, cataracts, one of the core clinical diagnostic features for DM2, may be absent because evaluation occurs early in the disease. However, molecular testing is not applicable as yet on a routine basis as is CTG expansion PCR or Southern Blot for DM1. The size and somatic instability of the DM2 repeat in fact, complicate the interpretation of data obtained by PCR and Southern analysis that sometimes fail to detect the DM2 expansions (Liquori et al., 2001; Bachinski et al., 2003; Day et al., 2003). To determine the presence of DM2 mutation, Bachinski et al. (2003) developed a repeat-primed PCR (RP-PCR), which used in combination with a Field Inversion Electrophoresis (FIGE) Southern blot also determines the size of the expansion. Furthermore, Day et al. (2003) describe a repeat assay (RA) based on the amplification of the genomic region with the repeat expansion followed by the Southern analysis of the PCR products. Although these tests increase the detection rate of the DM2 expansion, still they are expensive, not available as routine diagnostic test and much time consuming methods for DM2 diagnosis. Only recently nuclear clump type 2 fiber atrophy (Vihola et al., 2003) and type 2 fiber atro- 

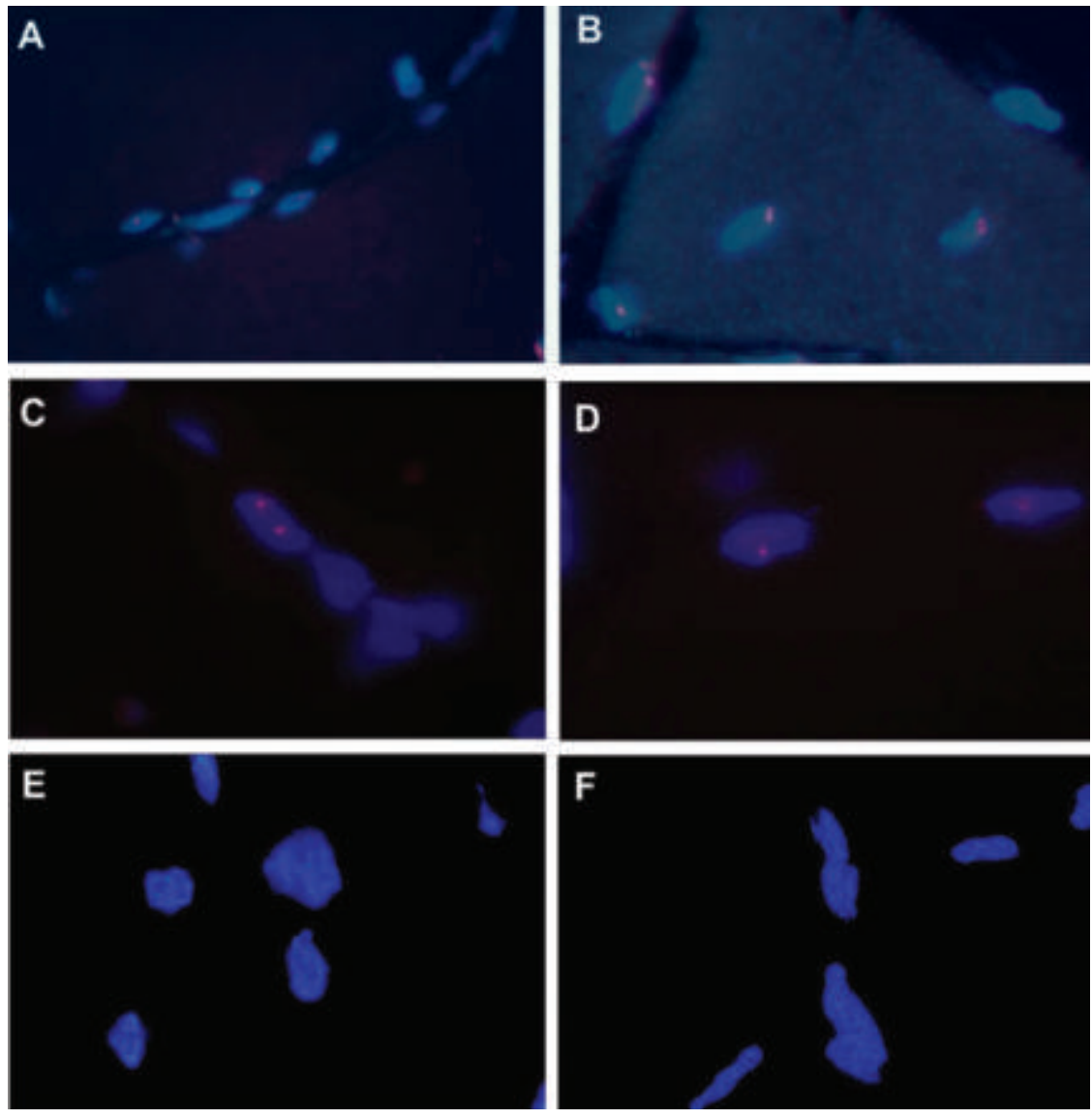

Figure 1. Fluorescence in situ hybridization (FISH) with (CAGG) 5 probe on muscle tissue. A-D. Ribonuclear inclusions (red) are present in myonuclei (blue) of muscle tissue from DM2 patients (A: original magnification 400x; $D$ original magnification 1000x). B. Mutant RNA foci (red) are also present in central nuclei (blue) of muscle tissue: note the rod shape of foci suggesting the confluence of 2 or more spot signals (original magnification 630x). C. Multiple ribonuclear inclusion in muscle nucleus in a DM2 patient (original magnification 1000x). E-F. Ribonuclear inclusions are absent in myonuclei in DM1 patient (E: original magnification $1000 x$ ) and in patient with other muscular disease (F: original magnification 1000x) phy (Schoser et al., 2004) have been found typical of DM2 and could be considered an useful tool to target subsequent biomolecular analysis.

Fluorescence in situ hybridization (FISH) is a powerful technique used to localize nucleic acid sequences within the cell. In the present study, fluorescent labelled antisense oligonucleotide probes to the CCUG repeat were hybridized to muscle biopsy tissue from genetically confirmed DM2 patients for the direct visualization of mutant RNA in myonuclei. Our aim was to asses if FISH could be used as a method to diagnose DM2, since the procedures for the application of this technique on tissues are quick, not very complex and share many similarities to those for immunohistochemistry, which is widely used in both basic research and diagnostic laboratories.

\section{Materials and Methods}

\section{Patients and tissue samples}

The diagnosis of DM2 was based upon the clinical diagnostic criteria set by the International Consortium for Myotonic Dystrophies (Moxley et al., 2002). A description of the clinical features of the DM2 patients used in this study are reported in Table I. Biceps brachii muscle biopsies from genetically confirmed DM2 patients $(n=17)$ were prepared by snap-freezing in cooled isopentane.

The histological diagnosis was performed on serial sections $(10 \mu \mathrm{m})$ of muscle biopsies from all of these patients processed for routine histological or histochemical stainings. A standard myofibrillar ATPase staining protocol was used after preincubation at $\mathrm{pH} 4.3, \mathrm{pH} 4.6$, and $\mathrm{pH} 9.4$ or 10.4 (Dubowitz, 1985). Antibodies against different myosin heavy chain ( $\mathrm{MHC}$ ) isotypes were used for immunohistochemical identification of fast and slow MHC fibers according to Vihola et al. (2003). The genetic confirmation of DM2 was performed by repeat assay described by Bachinski et al. (2003).

Muscle biopsies from patients with myotonic dystrophy type $1\left(D_{1 M} ; n=5\right)$ or with other muscular diseases $(n=17)$ were used as controls. The biopsies were used for this study after informed consent from patients.

\section{Fluorescence In Situ Hybridization (FISH)}

Transverse muscle cryostat sections $(6 \mu \mathrm{m})$ were 

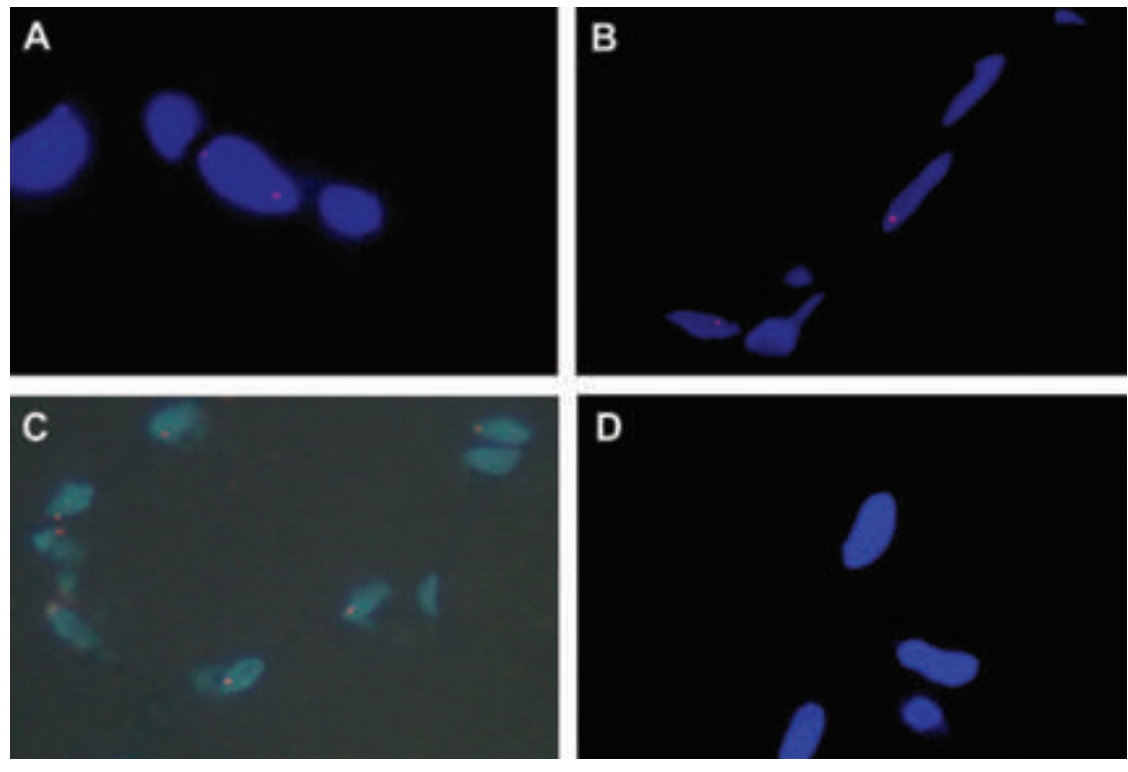

Figure 2. Fluorescence in situ hybridization (FISH) with (CAG) 6 CA probe on muscle tissue. A,B. Ribonuclear inclusions (red) are present in nuclei (blue) of muscle tissue from DM1 patients (A: original magnification 1000x; B original magnification 1000x). C. ribonuclear inclusion (red) are also present in nuclei (blue) of muscle tissue from DM2 patient (original magnification 400x).D. No foci are present in myonuclei in patient with other muscular diseases (F: original magnification $1000 x$ ) dried for $30 \mathrm{~min}$ at room temperature and fixed in $2 \%$ paraformaldehyde for $30 \mathrm{~min}$ at $4^{\circ} \mathrm{C}$. After fixation, sections were washed five times in phosphatebuffered saline (PBS) for $3 \mathrm{~min}$ at room temperature, and permeabilized in $2 \%$ acetone PBS (prechilled at $-20^{\circ} \mathrm{C}$ ) for $5 \mathrm{~min}$. After washing in PBS, sections were incubated in 30\% formamide and $2 \times S S C$ for $10 \mathrm{~min}$ at room temperature and then hybridized with probe $\left(1 \mathrm{ng} / \mu \mathrm{L}\right.$ for $2 \mathrm{~h}$ at $37^{\circ} \mathrm{C}$ in $30 \%$ formamide, $2 \times S S C, 0.02 \%$ BSA, $67 \mathrm{ng} / \mu \mathrm{L}$ yeast tRNA, 2 mM vanadyl ribonucleoside complex. Sections were washed first in 30\% formamide and $2 \times S S C$ at $45^{\circ} \mathrm{C}$ for $30 \mathrm{~min}$, then in $1 \times S S C$ and $165 \mathrm{nM}$ 4,6 diamidino-2-phenylindole (DAPI) at room temperature for $30 \mathrm{~min}$. Sections were then mounted with Gel Mount mounting medium (Biomedia Corp). Probes were HPLC-purified 2-0methhyl RNA CAGG or CAG repeat 20-mers and 5'Texas red labelled (IDT, Coralville, IA). Muscle sections were examined using a fluorescence microscope or sometimes using a confocal microscope. In order to get the same treatment, one section from both DM2 and control patient muscle tissue were placed on the same slide.

\section{Results}

Fluorescently-labelled antisense oligonucleotide $(C A G G)_{5}$ probe was used for in situ hybridization to detect the ribonuclear inclusions containing the CCUG expansion in muscles from genetically confirmed DM2 patients. Intense nuclear foci of hybridization were observed in muscle tissue from each of 17 DM2 individuals considered (Figures IA-D). The number of foci was 1 to 3 per nucleus with no foci detected in the cytoplasm (Figures $1 A$, $B)$. In contrast, no nuclear foci were detected when $(C A G G)_{5}$ probe was hybridized to muscle tissue from DMI patients or from subjects with other muscle diseases used as controls (Figures $1 \mathrm{E}, \mathrm{F}$ ). $(C A G G)_{5}$ probe generated a high background in the nucleoplasm both in DM2, DMI and control muscles, but foci of hybridization were easily distinguished since they resulted more intensely fluorescent than the background hybridization. When $(\mathrm{CAG})_{6} \mathrm{CA}$ probe was hybridized to DM2 muscle tissue, mutant RNA was also identified and RNA foci appeared to be smaller and less fluorescent

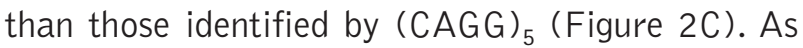
expected, $(C A G)_{6} C A$ probe also evidenced ribonuclear inclusions myonuclei of DMI muscle sections (Figure 2A, B). Indeed DMI patients, unlike DM2 patients, have an abnormally high number of CTG repeats in the gene for myotonic dystrophy (DM protein kinase gene) (Brook et al., 1992; Mahadevan et al., 1992). As for DM2, mutant transcripts containing the expanded repeats are retained in myonuclei producing inclusions similar to those of DM2 (Taneja et al., 1995). Nuclear foci were not observed in control muscle sections hybridized with $(C A G)_{6} C A$ probe (Figure $2 D$ ). No nuclear background was observed in any muscle sections when hybridized with $(C A G)_{6} C A$ probe. In summary our results show that $(C A G G)_{5}$ probe 
identifies ribonuclear inclusions in DM2 patients only, whereas $(C A G)_{6} C A$ probe can detect foci of mutant RNA both in DMI and DM2 patients.

\section{Discussion}

Conventional genetic tests used for myotonic dystrophy type 1 diagnosis, such as Southern blot analysis or PCR, are not reliable for DM2 identification (Liquori et al., 2001; Bachinski et al., 2003; Day et al., 2003). Molecular diagnostic protocols, recently described by Bachinski et al. (2003) and by Day et al. (2003), can be used for detecting the DM2 mutation, but are still too long and complicated to be part of routine laboratory diagnostics. In agreement with previous data (Liquori et al., 2001; Mankodi et al., 2003; Sallinen et al., 2004), the present study clearly demonstrates that the DM2 mutation can be identified by FISH using CAGG probe to visualize nuclear foci in muscle biopsies. Moreover, our results show a consistent detection of ribonuclear inclusions by $(C A G G)_{5}$ in DM2 muscles and their absence in $\mathrm{DMI}$ and in other control muscles, suggesting that the use of this probe allows a specific method for DM2 diagnosis. Performing FISH with CAG oligonucleotides instead, reveals ribonuclear inclusions both in DM1 and DM2 muscles as previously reported by other Authors (Mankodi et al., 2001, 2003). This aspecific finding indicates that $(C A G)_{6} C A$ probe cannot be used for a differential diagnosis between DM2 and DMl.

It is worth emphasizing that ribonuclear inclusions by FISH, were present irrespective of degree of muscle involvement or of severity of clinical involvement. Three of 17 patients had normal histograms, with no preferential nuclear clump type II fiber atrophy as is usually found in DM2. Yet FISH demonstrated nuclear foci in these patients.

The nuclear accumulation of mutant RNA in DM1 and DM2 muscle tissue, is a molecular feature shared by these two disorders. This may indicate that some characteristic they share, like myotonia, cardiac arrhythmias and insulin resistance, as well as other aspects of the multisystemic involvement of these disorders, result from a common mechanism such as altered RNA splicing of several genes. Alteration of the chloride channel splicing leads to the loss of chloride channel protein that results in myotonia (Charlet et al., 2002; Mankodi et al., 2002); changes in cardiac troponin T splicing (Philips et al., 1998) may be implicated in the cardiac disfunction; insulin receptor splicing alterations in DM2 may be implicated in insulin resistance which characterizes the disease (Savkur et al., 2001, 2004). The role of ribonuclear inclusions in disease pathogenesis remains unclear. Nevertheless ribonuclear inclusions and splicing changes are present before any histological abnormality manifestations (Mankodi et al., 2001; Savkur et al., 2004). This could be important for an early diagnosis before the spectrum of clinical signs of muscle disease appear.

In conclusion, FISH with (CAGG) ${ }_{5}$ is a method that allows the direct visualization of the mutant RNA on muscle biopsy. Therefore it may be a simple approach for DM2 diagnosis, which can be performed in a rapid and sensitive manner in any pathology laboratory. Moreover, it permits a differential diagnosis between DM2 and DM1. We suggest that FISH with (CAGG) 5 should be considered as a routine laboratory procedure to confirm or refute the clinical suspicion of DM2. It should also be applied routinely to screen patients with myotonic disorders. This procedure may contribute for example to differentiate chloride channelopathies from DM2 and better target subsequent genetic screening. It may also allow to recognize preclinical or sporadic presentations of DM2 in patients with unknown neuromuscular disorders or asymptomatic high CK levels, in whom a biopsy is performed for diagnostic purposes.

\section{Acknowledgements}

This study was supported by MURST $60 \%$ to G. Meola.

\section{References}

Bachinski LL, Udd B, Meola G, Sansone V, Bassez G, Eymard B, et al. Confirmation of the type 2 myotonic dystrophy (CCTG)n expansion mutation in patients with proximal myotonic myopathy/proximal myotonic dystrophy of different European origins: a single shared haplotype indicates an ancestral founder effect. Am J Hum Genet 2003; 73:835-48.

Brook JD, McCurrach ME, Harley HG, Buckler AJ, Church D, Aburatani $\mathrm{H}$, et al. Molecular basis of myotonic dystrophy: expansion of a trinucleotide (CTG) repeat at the $3^{\prime}$ end of a transcript encoding a protein kinase family member. Cell 1992; 68:799-808.

Charlet BN, Savkur RS, Singh G, Philips AV, Grice EA, Cooper TA. Loss of the muscle-specific chloride channel in type 1 myotonic dystrophy due to misregulated alternative splicing. Mol Cell 2002; 10:45-53.

Day JW, Ricker K, Jacobsen JF, Rasmussen LJ, Dick BA, Kress W, et al. Myotonic dystrophy type 2: molecular, diagnostic and clinical spectrum. Neurology 2003; 60:657-64.

Dubowitz V. Muscle biopsy: a practical approach. Bailliére Tindall, London 1985; 19-40.

Fardaei M, Rogers MT, Thorpe HM, Larkin K, Hamshere MG, Harper $P S$, et al. Three proteins, MBNL, MBLL and MBXL, co-localize in 


\section{R. Cardani et al.}

vivo with nuclear foci of expanded repeat transcripts in DMI and DM2 cells. Hum Mol Genet 2002; 11:805-14.

Kanadia RN, Johnstone KA, Mankodi A, Lungu C, Thornton CA, Esson $D$, et al. A muscleblind knockout model for myotonic dystrophy. Science 2003; 302:1978-80.

Liquori CL, Ricker K, Moseley ML, Jacobsen JF, Kress W, Naylor SL et al. Myotonic dystrophy type 2 caused by a CCTG expansion in intron 1 of ZNF9. Science 2001; 293:816-17.

Mahadevan M, Tsilfidis C, Sabourin L, Shulter G, Amemiya C, Jansen $G$, et al. Myotonic dystrophy mutation: an unstable CTG repeat in the $3^{\circ}$ untranslated region of the gene. Science 1992; 255:1253-55.

Mankodi A, Urbinati CR, Yuan QP, Moxley RT, Sansone V, Krym M, et al. Muscleblind localizes to nuclear foci of aberrant RNA in myotonic dystrophy types 1 and 2. Hum Mol Genet 2001; 10:2165-70.

Mankodi A, Takahashi MP, Jiang H, Beck CL, Bowers WJ Moxley RT, et al. Expanded CUG repeats trigger aberrant splicing of $\mathrm{CIC}-1$ chloride channel pre-mRNA and hyperexcitability of skeletal muscle in myotonic dystrophy. Mol Cell 2002; 10:35-44.

Mankodi A, Teng-Umnuay $P$, Krym M , Henderson D, Swanson M Thornton CA. Ribonuclear inclusions in skeletal muscle in myotonic dystrophy types 1 and 2. Ann Neurol 2003; 54:760-68.

Meola G, Moxley RT. Myotonic disorders: myotonic dystrophy and proximal myotonic myopathy. In: Schapira AHV, Griggs RC, eds Muscle disorders. Butterworth-Heinemann, Boston 1999; 115-34.

Meola G. Myotonic dystrophies. Curr Opin Neurol 2000; 13:519-25.

Meola G, Sansone V, Rotondo G, Pazzi A, Gandossini S, Cardani R et al. Type 2 fiber atrophy targets biomolecular diagnosis in PROMM/DM2 but FISH confirms final genetic analysis in muscle biopsy. BAM 2004;14:106-07.

Moxley RT, Udd B, Ricker K. 54th ENMC International Workshop: PROMM (Proximal Myotonic Myopathies) and other Proxima Myotonic Syndromes-Workshop Report. Neuromuscul Disord 1998 8:508-18.
Moxley 3rd RT, Meola G, Udd B, Ricker K. Report of the 84th ENMC workshop: PROMM (proximal myotonic myopathy) and other myotonic dystrophy-like syndromes. Neuromuscul Disord 2002; 12:306-17.

Philips AV, Timchenko LT, Cooper TA. Disruption of splicing regulated by a CUG-binding protein in myotonic dystrophy. Science 1998; 280:737-41.

Ranum LPW, Rasmussen P, Benzow K, Koob M, Day JW. Genetic mapping of a second myotonic dystrophy locus. Nat Genet 1998; 19:196-8.

Sallinen R, Vihola A, Bachinski LL, Huoponen K, Haapasalo $H$, Hackman $\mathrm{P}$, et al. New methods for molecular diagnosis and demonstration of the (CCTG)n mutation in myotonic dystrophy type 2 (DM2). Neuromuscul Disord 2004; 14:274-83.

Savkur RS, Philips AV, Cooper TA Aberrant regulation of insulin receptor alternative splicing is associated with insulin resistance in myotonic dystrophy. Nat Genet 2001; 29:40-47.

Savkur RS, Philips AV, Cooper TA, Dalton JC, Moseley ML, Ranum $L P W$, et al. Insulin receptor splicing alteration in myotonic dystrophy type 2. Am J Hum Genet 2004; 74:1309-13.

Schoser BGH, Schneider-Gold C, Kress W, Goebel H, Reilich P, Koch $\mathrm{MC}$, et al. Muscle pathology in 57 patients with myotonic dystrophy type 2. Muscle Nerve 2004;29:275-81.

Taneja KL, McCurrach M, Schalling M, Housmann D, Singer RH. Foci of trinucleotide repeat transcripts in nuclei of myotonic dystrophy cells and tissue. J Cell Biol 1995; 128:995-1002.

Udd B, Meola G, Krahe R, Thornton C, Ranum L, Day J, et al. Report of the 115th ENMC workshop: DM2/PROMM and other myotonic dystrophies. Neuromuscul Disord 2003; 13;589-96.

Vihola A, Bassez G, Meola G, Zhang S, Haapasalo H, Paetau A, et al. Histopathological differences of myotonic dystrophy type 1 (DM1) and PROMM/DM2. Neurology 2003; 60:1854-57. 